Article

\title{
Analysis of the Gas Phase Acidity of Substituted Benzoic Acids Using Density Functional Concepts
}

\author{
Jorge A. Amador-Balderas ${ }^{1}$, Michael-Adán Martínez-Sánchez ${ }^{2}$, Ramsés E. Ramírez ${ }^{1, * \mathbb{C} \text {, }}$ \\ Francisco Méndez $2,3,4, *$ (D) and Francisco J. Meléndez ${ }^{5}$ \\ 1 Departamento de Fisicomatemáticas, Facultad de Ciencias Químicas, Av. San Claudio y 14 Sur, \\ Col. San Manuel, Benemérita Universidad Autónoma de Puebla, C.P. 72570, Puebla, Pue., Mexico \\ 2 Departamento de Química, División de Ciencias Básicas e Ingeniería, Universidad Autónoma \\ Metropolitana-Iztapalapa, A.P. 55-534, Mexico, D.F., 09340 Mexico \\ 3 Le Studium Guest Research Fellow, Loire Valley Institute for Advanced Studies, 4500 Orleans \& Tours, France \\ 4 Conditions Extrêmes et Matériaux: Haute Température et Irradiation (CEMHTI), UPR3079 CNRS, \\ CEMHTI 1, Avenue de la Recherche Scientifique, 45071 Orleans, France \\ 5 Departamento de Fisicoquímica, Facultad de Ciencias Químicas, Av. San Claudio y 14 Sur, Col. San Manuel, \\ Benemérita Universidad Autónoma de Puebla, C.P. 72570, Puebla, Pue., Mexico \\ * Correspondence: ramses.ramirez@correo.buap.mx (R.E.R.); fm@xanum.uam.mx (F.M.); \\ Tel.: +52-55-58044600 (ext. 3282) (F.M.); +52-22-22295500 (ext. 3974) (R.E.R.)
}

Academic Editor: Luis R. Domingo

Received: 4 February 2020; Accepted: 29 March 2020; Published: 2 April 2020

\begin{abstract}
A theoretical study of the effect of the substituent $Z$ on the gas phase acidity of substituted benzoic acids $\mathrm{ZC}_{6} \mathrm{H}_{4} \mathrm{COOH}$ in terms of density functional theory descriptors (chemical potential, softness and Fukui function) is presented. The calculated gas phase $\Delta_{\text {acid }} G^{\circ}$ values obtained were close to the experimental ones reported in the literature. The good relationship between the $\Delta_{\text {acid }} G^{\circ}$ values and the electronegativity of $\mathrm{ZC}_{6} \mathrm{H}_{4} \mathrm{COOH}$ and its fragments, suggested a better importance of the inductive than polarizability contributions. The balance of inductive and resonance contributions of the substituent in the acidity of substituted benzoic acids showed that the highest inductive and resonance effects were for the $-\mathrm{SO}_{2} \mathrm{CF}_{3}$ and $-\mathrm{NH}_{2}$ substituents in the para- and ortho-position, respectively. The Fukui function confirmed that the electron-releasing substituent attached to the phenyl ring of benzoic acid decreased the acidity in the trend ortho $>$ meta $>$ para, and the electron-withdrawing substituent increased the acidity in the trend ortho $<$ meta $<$ para.
\end{abstract}

Keywords: absolute gas phase acidity; Fukui function; chemical potential; softness; nucleophile; electrophile; inductive effect; resonance effect; polarizability effect

\section{Introduction}

The Hammett equation $\left(\log K_{\mathrm{a}}{ }^{\mathrm{X}} / \log K_{\mathrm{a}}{ }^{\mathrm{H}}=\sigma \rho\right)$ is a linear Gibbs free energy relationship (a link between equilibrium constant and reaction rates) that uses the properties of substituted benzoic acids as a reference standard to study the effect of substituent on the reactivity and properties of various molecules [1]. Although the Hammett equation is fulfilled in the meta- and para-substituted benzoic acids (the correlation of acidity with the $\sigma$ scale is obtained), it is not obeyed for the ortho-isomers $[2,3]$. Exner et al. [3] have suggested that the main part of ortho effects in the acidity of substituted benzoic acids is due to inductive and resonance effects and steric effects are of limited importance for acidity. Verevkin et al. [4] evaluated the thermochemical properties of methylbenzoic and methoxybenzoic acids and found that the conformational peculiarities of the ortho-methoxybenzoic acid have not relevance for the enthalpy of formation of this molecule. Taft et al. [5-7], Exner et al. [8,9] and Geerlings et al. $[10,11]$ have pointed out the usefulness of the polarizability to the analysis of structural 
effects in proton-transfer reactions in gas phase. Chattaraj et al. [12] found trends of changes in acidity of meta- and para-substituted benzoic acids with electrophilicity based charge transfer index, fractional number of electrons transferred and group charge. Liu et al. [13] employed molecular electrostatic potential and the valence natural atomic orbitals to predict the acidity of 196 singly, doubly, and triply substituted benzoic acids. (the ortho-benzoic acids were excluded). Vianello and Maksic [14] found that the acidity in a series of para-substituted benzoic acids increased with the stability of the corresponding conjugate bases. Hollingsworth et al. [15] examined the effects of substituents on the pKas of a set of 16 meta- and para-substituted benzoic acids using density functional theory [B3LYP/6-311G(d,p)] calculations, they found a good correlations with the Löwdin, Mulliken, AIM, and natural population analysis charges on atoms of the dissociating carboxylic acid group. Méndez et al. studied the effect of substituent on the acidity and reactivity of para-substituted phenols [16-18], ethanol derivatives [19] and their anions and found that the extension of the charge dispersal in the anions was the key to understanding the gas-phase acidity $[17,20]$. In addition to the analytical equations, developed from the density functional theory (DFT) [21] and the hard and soft acids and bases (HSAB) principle [22,23] showed the mathematical relationship between the gas phase acidity and the hydrogen charge [16].

Most of the previous studies have evaluated the acidity of the meta- and para-substituted benzoic acids, while in general the ortho-substituted has been excluded. Therefore, in this paper we focused our attention in the effect of the substituent $Z$ on the gas phase acidity of a set of ortho-, meta- and para-substituted benzoic acids $\mathrm{ZC}_{6} \mathrm{H}_{4} \mathrm{COOH}(\mathbf{1 a}-\mathbf{6 c}$, Figure 1) in terms of the density functional theory descriptors electronegativity $\chi[21]$ and softness $S$ (related with the inductive and polarizability effects, respectively [24-28]) of substituent $(\mathrm{Z})$ and fragments $\left(\mathrm{ZC}_{6} \mathrm{H}_{4}, \mathrm{ZC}_{6} \mathrm{H}_{4} \mathrm{COO}\right)$. We found that there is a good relationship between the acidity of substituted benzoic acids and the electronegativity of $\mathrm{ZC}_{6} \mathrm{H}_{4}$, $\mathrm{ZC}_{6} \mathrm{H}_{4} \mathrm{COO}$ and $\mathrm{ZC}_{6} \mathrm{H}_{4} \mathrm{COOH}$ indicating the importance of the inductive contributions. While for the softness of $\mathrm{ZC}_{6} \mathrm{H}_{4} \mathrm{COOH}$ and its fragments there is not a relationship with the acidity, suggesting less importance of the polarizability contributions. The Fukui function, a density functional theory (DFT) descriptor related with the resonance effect [20,29], showed that the electron-releasing substituent attached to the phenyl ring of benzoic acid (1a-3c) decreases the acidity in the trend ortho $>$ meta $>$ para, and the electron-withdrawing substituent $(\mathbf{4 a}-\mathbf{6 c})$ increases the acidity in the trend ortho $<$ meta $<$ para.

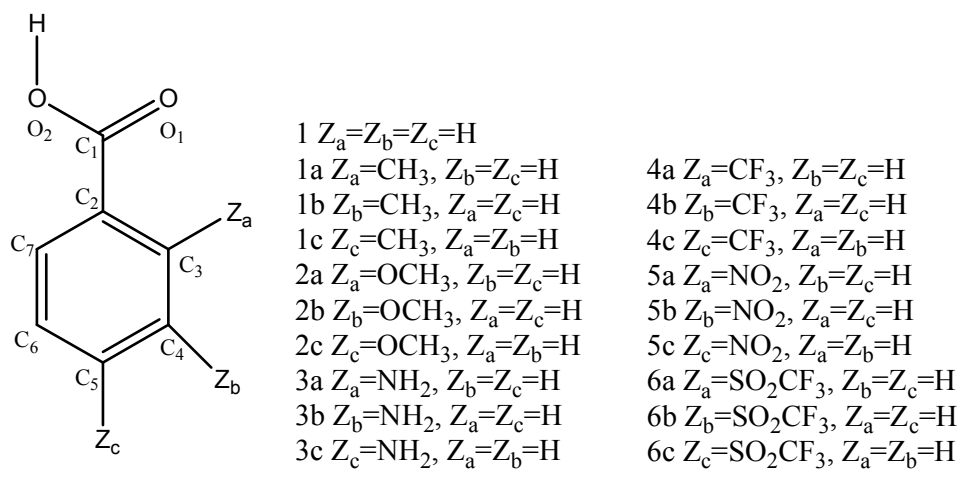

Figure 1. Substituted benzoic acids.

\section{Results and Discussion}

Scheme 1 shows the ionization reaction in the gas phase for the substituted benzoic acids. 


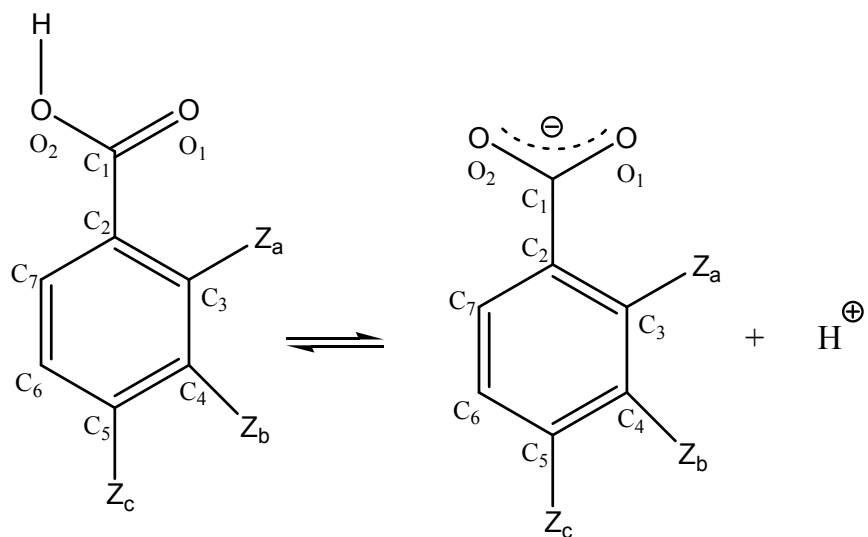

Scheme 1. The ionization reactions for $\mathrm{ZC}_{6} \mathrm{H}_{4} \mathrm{COOH}$.

Table 1 shows our gas phase acidity values calculated at the B3LYP/6-311++G(2d,2p) level of theory using GAUSSIAN09 [30] for 1a-6c, they were obtained as $\Delta_{\text {acid }} G^{\circ}=G^{\circ}$ (anion) $+G^{\circ}\left(\mathrm{H}^{+}\right)-G^{\circ}$ (acid). The calculated $\Delta_{\text {acid }} G^{\circ}$ values were close to the experimental values reported in the literature (see Table 1) [31]. Linear regression analysis shows that there is a good correlation between experimental and theoretical $\Delta_{\text {acid }} G^{\circ}$ values with $R^{2}=0.98$ (Figure 2).

Table 1. Absolute gas phase acidities for 1a-6c. The values are reported in $\mathrm{kcal} / \mathrm{mol} . \Delta_{\text {acid }} G^{\circ}=$ $\mathrm{G}^{\circ}$ (anion) $+\mathrm{G}^{\circ}\left(\mathrm{H}^{+}\right)-G^{\circ}$ (acid). The experimental values are given in parentheses and were obtained from http://webbook.nist.gov/chemistry/ [31].

\begin{tabular}{ccccccc}
\hline & $\mathbf{1}$ & $\mathbf{2}$ & $\mathbf{3}$ & $\mathbf{4}$ & $\mathbf{5}$ & $\mathbf{6}$ \\
\hline & 331.09 & 330.21 & 331.03 & 325.99 & 321.86 & 319.06 \\
$\mathbf{a}$ & $(332.46 \pm 2.01)$ & $(332.46 \pm 2.01)$ & $(330.31 \pm 2.01)$ & $(-)$ & $(324.33 \pm 2.01)$ & $(-)$ \\
& 332.76 & 332.47 & 333.62 & 324.34 & 320.51 & 318.19 \\
b & $(333.65 \pm 2.01)$ & $(332.46 \pm 2.01)$ & $(334.61 \pm 2.01)$ & $(325.29 \pm 2.01)$ & $(322.18 \pm 2.01)$ & $(-)$ \\
& 333.35 & 333.97 & 336.24 & 323.61 & 319.13 & 316.87 \\
c & $(333.89 \pm 2.01)$ & $(333.89 \pm 2.01)$ & $(336.28 \pm 2.01)$ & $(325.29 \pm 2.01)$ & $(320.98 \pm 2.01)$ & $(-)$ \\
\hline
\end{tabular}

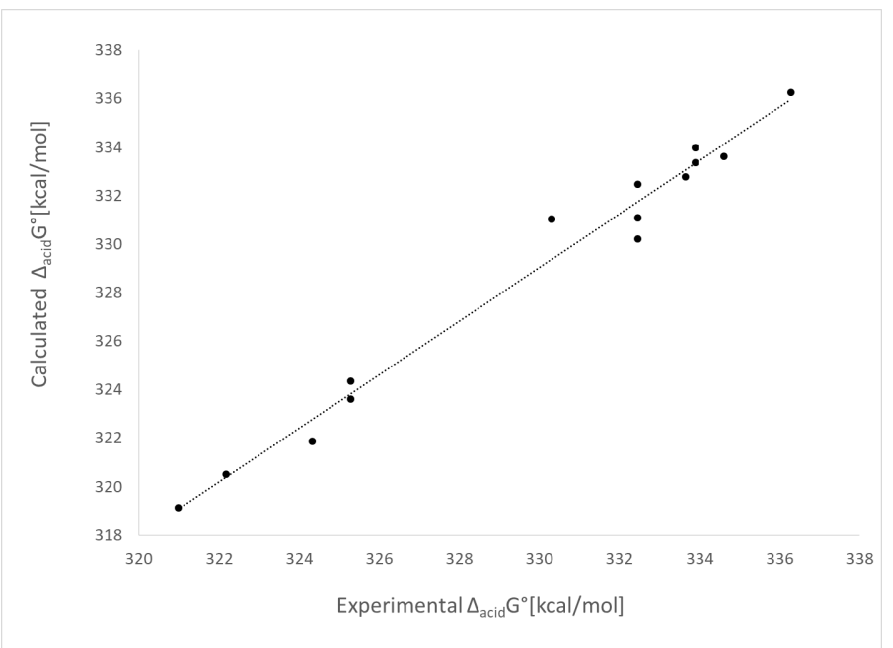

Figure 2. Calculated $\Delta_{\text {acid }} \mathrm{G}^{\circ}$ vs experimental $\Delta_{\text {acid }} \mathrm{G}^{\circ}$ values for a set of substituted benzoic acids. Gas phase acidity in $\mathrm{kcal} / \mathrm{mol}, \mathrm{R}^{2}=0.98$.

The calculated gas phase acidity values are consistent with the substituent electronic effect, being the benzoic acid with substituent $\mathrm{NH}_{2}$ (compounds $3 \mathbf{a}-\mathbf{3} \mathbf{c}$ ) and $\mathrm{SO}_{2} \mathrm{CF}_{3}$ (compounds $6 \mathbf{a}-\mathbf{6 c}$ ) the least and most acidic, respectively; they correspond to the two extremes for which $\delta \Delta_{\text {acid }} G^{\circ}=19.37 \mathrm{kcal} / \mathrm{mol}$. 
Interesting for the electron-releasing substituent attached to the phenyl ring the acidity follows the trend ortho $>$ meta $>$ para, and the average value for the two extremes is $\delta \Delta_{\text {acid }} G^{\circ}=3.7 \mathrm{kcal} / \mathrm{mol}$, while for electron-withdrawing substituent the acidity follows the trend ortho < meta < para, and the average value for the two extremes is $\delta \Delta_{\text {acid }} G^{\circ}=2.4 \mathrm{kcal} / \mathrm{mol}$.

Considering that the steric effects are of limited importance for acidity [3] and the usefulness of the electronegativity and polarizability [24-28], we study the electronic effect of the substituent $Z$ in the acidity of the substituted benzoic acids using a two parameter linear model $\Delta_{\text {acid }} G^{\circ}=\mathrm{m} x+\mathrm{b}$, where $x$ is the electronegativity $\chi$ or softness $S$ of $\mathrm{Z}, \mathrm{C}_{6} \mathrm{H}_{4}, \mathrm{ZC}_{6} \mathrm{H}_{4}, \mathrm{ZC}_{6} \mathrm{H}_{4} \mathrm{COO}$ and $\mathrm{ZC}_{6} \mathrm{H}_{4} \mathrm{COOH}$ (we have observed that the model of two parameters is sufficient for cyclic derivatives [17], while for acyclic derivatives the best-fitting values were achieved for a triple-parameter equation [19]). The electronegativity and softness of $\mathrm{ZC}_{6} \mathrm{H}_{4} \mathrm{COOH}$ were obtained as the negative of the chemical potential $\mu$ and the inverse of the hardness $S=1 /(2 \eta)$, respectively, where $\mu=-(I+A) / 2=-\chi$ and $\eta=(I-A) / 2$, where $I$ is the ionization potential and $A$ the electron affinity [21]. The electronegativity and softness for the fragments $\mathrm{Z}, \mathrm{C}_{6} \mathrm{H}_{4}, \mathrm{ZC}_{6} \mathrm{H}_{4}$ and $\mathrm{ZC}_{6} \mathrm{H}_{4} \mathrm{COO}$ were obtained using the condensed Fukui function for each fragment and the Hirshfeld charges analysis [32,33].

Table 2 shows the two-parameter correlation analysis for $S_{\text {fragment }}$ and $\Delta_{\text {acid }} G^{\circ}$, the poor correlation coefficient values obtained shows that there is not direct relationship between $\Delta_{\mathrm{acid}} G^{\circ}$, and the softness of $\mathrm{Z}, \mathrm{ZC}_{6} \mathrm{H}_{4}, \mathrm{ZC}_{6} \mathrm{H}_{4} \mathrm{COO}$ and $\mathrm{ZC}_{6} \mathrm{H}_{4} \mathrm{COOH}$. The nonlinearity suggesting that the polarizability contribution has not an important role in the acidity of substituted benzoic acids. Instead, Table 3 shows that there is a good linear correlation between $\chi_{\text {fragment }}$ and $\Delta_{\text {acid }} G^{\circ}$ for $\mathrm{ZC}_{6} \mathrm{H}_{4}, \mathrm{ZC}_{6} \mathrm{H}_{4} \mathrm{COO}$ and $\mathrm{ZC}_{6} \mathrm{H}_{4} \mathrm{COOH}$. The acidity of the substituted benzoic acids increases when the electronegativity of the fragments $\mathrm{ZC}_{6} \mathrm{H}_{4}, \mathrm{ZC}_{6} \mathrm{H}_{4} \mathrm{COO}$ increases. The nonlinearity between the electronegativity of the substituent $Z$ and $\Delta_{\text {acid }} G^{\circ}$ suggesting that there is no direct interaction between the substituent and the hydrogen atom of the carboxylic group. Therefore, the substituent $Z$ transmits its inductive effect through the $\pi$ system of the benzene ring $\mathrm{C}_{6} \mathrm{H}_{4}$ and the hydrogen atom of the carboxylic group shows the effect of the electronegativity of the whole fragment $\mathrm{ZC}_{6} \mathrm{H}_{4} \mathrm{COO}$. This is consistent with the good relationship obtained between the hydrogen charge and the $\Delta_{\text {acid }} G^{\circ}$ (Table 2) [16].

Table 2. Two parameter correlation analysis $\Delta_{\text {acid }} G^{\circ}(\mathrm{kcal} / \mathrm{mol})=\mathrm{b}+\mathrm{m} S_{\text {fragment }}\left(\mathrm{eV}^{-1}\right)$ for $\mathbf{1 a}-\mathbf{6 c}$.

\begin{tabular}{ccc}
\hline Fragment & Position & $\mathbf{R}^{\mathbf{2}}$ \\
\hline $\mathrm{Z}$ & $o$ & 0.1974 \\
& $m$ & 0.0004 \\
$\mathrm{C}_{6} \mathrm{H}_{4}$ & $p$ & 0.0493 \\
& $o$ & 0.5038 \\
& $m$ & 0.855 \\
$\mathrm{ZC}_{6} \mathrm{H}_{4}$ & $p$ & 0.8021 \\
& $o$ & 0.0011 \\
& $m$ & 0.4267 \\
$\mathrm{ZC}_{6} \mathrm{H}_{4} \mathrm{COO}$ & $p$ & 0.227 \\
& $o$ & 0.0089 \\
& $m$ & 0.31 \\
$\mathrm{ZC}_{6} \mathrm{H}_{4} \mathrm{COOH}$ & $p$ & 0.0026 \\
& $o$ & 0.0034 \\
& $m$ & 0.2933 \\
$\mathrm{qH}$ & $p$ & 0.0008 \\
& $o$ & 0.9239 \\
& $m$ & 0.9938 \\
& $p$ & 0.9903 \\
\hline
\end{tabular}


Table 3. Two parameter correlation analysis $\Delta_{\text {acid }} G^{\circ}(\mathrm{kcal} / \mathrm{mol})=\mathrm{b}+\mathrm{m} \chi_{\text {fragment }}(\mathrm{eV})$ for $\mathbf{1 a}-\mathbf{6 c}$.

\begin{tabular}{ccc}
\hline Fragment & Position & $\mathbf{R}^{\mathbf{2}}$ \\
\hline $\mathrm{Z}$ & $o$ & 0.7333 \\
& $m$ & 0.5409 \\
& $p$ & 0.0125 \\
$\mathrm{C}_{6} \mathrm{H}_{4}$ & $o$ & 0.4642 \\
& $m$ & 0.6352 \\
& $p$ & 0.6654 \\
$\mathrm{ZC}_{6} \mathrm{H}_{4}$ & $o$ & 0.9415 \\
& $m$ & 0.8498 \\
& $p$ & 0.8699 \\
$\mathrm{ZC}_{6} \mathrm{H}_{4} \mathrm{COO}$ & $o$ & 0.8422 \\
& $m$ & 0.920 \\
& $p$ & 0.9746 \\
$\mathrm{ZC}_{6} \mathrm{H}_{4} \mathrm{COOH}$ & $o$ & 0.8266 \\
& $m$ & 0.9206 \\
& $p$ & 0.9711 \\
\hline
\end{tabular}

We have shown previously that the resonance hybrid structure can be described in terms of the Fukui function $[19,29]$. The Fukui function $f(\mathbf{r})$ represents the change of the electron density $\rho(\mathbf{r})$ in a given point with respect to the change in the number of electrons $N, f(\mathbf{r})=(\partial \rho(\mathbf{r}) / \partial N)_{v(\mathbf{r})}$ and the relationship between $f(\mathbf{r})$ and the change of energy $E$ of the system produced by the charge redistribution due to the loss or gain of an electron is obtained from $f(\mathbf{r})=(\partial(\delta E / \delta v) / \partial N)$ [21]. The charge redistribution in the benzoic acid triggered by the substituent can be obtained from the Fukui function for electrophilic attack $f^{-}(\mathbf{r})=\rho_{N}(\mathbf{r})-\rho_{N-1}(\mathbf{r})$ (for loss an electron), and nucleophilic attack $f^{+}(\mathbf{r})=\rho_{N+1}(\mathbf{r})-\rho_{N}(\mathbf{r})$ (for gain an electron), where $\rho_{N}(\mathbf{r}), \rho_{N-1}(\mathbf{r})$ and $\rho_{N+1}(\mathbf{r})$ are the electron density of the species with $\mathrm{N}, \mathrm{N}-1$ and $\mathrm{N}+1$ electrons, respectively [34]. Therefore, we considered $f^{-}(\mathbf{r})$ and $f^{+}(\mathbf{r})$ for the substituted benzoic acids with electron-releasing and electron-withdrawing substituent, respectively. Figure 3 shows that the largest value of $f^{-}(\mathbf{r})$ for $\mathbf{1 a}-\mathbf{3} \mathbf{c}$ is located in general in the $\mathrm{C}$ atom opposite to the site where the substituent is located: the C-6, C-7 and C-2 atoms for the ortho-, meta- and para-position, respectively. Those atoms will be the most reactive because in the electronic redistribution they are the most suitable to give electron to an electrophile and according with the local HSAB principle [23] they will interact with soft electrophiles. As we can observe, these atoms will be the richest in electron density, and to the extend that they are further away from the carboxyl group they will interact less with it and allow the hydrogen atom to disassociate as a proton more easily. Therefore, the electron-releasing substituent $\left(\mathrm{CH}_{3}, \mathrm{OCH}_{3}\right.$ and $\left.\mathrm{NH}_{2}\right)$ will increase the acidity of the benzoic acid in the trend ortho- $>$ meta- > para-position. 


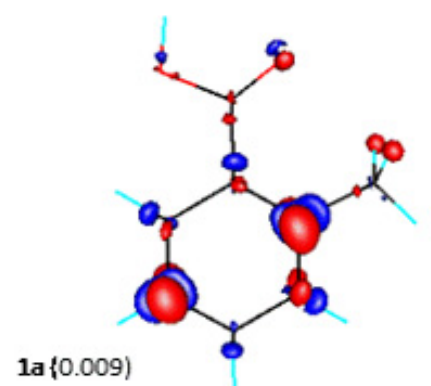

2a $\{0.012\}$

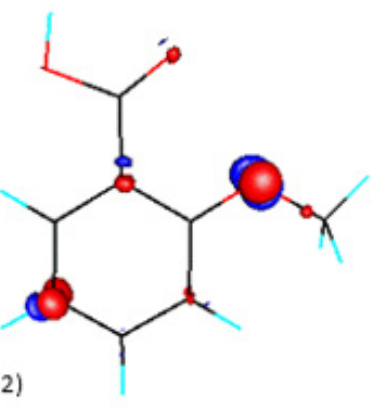

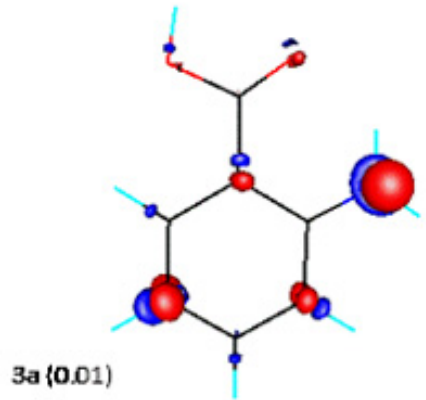

16

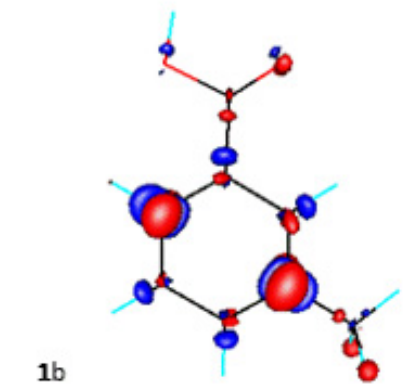

$2 b$

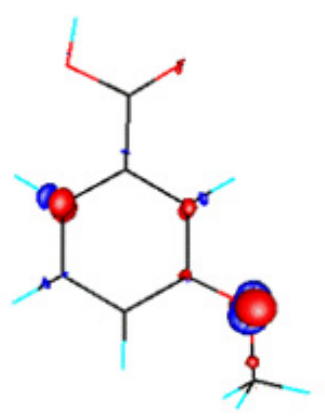

$1 c$

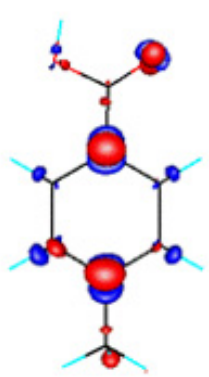

$2 c$

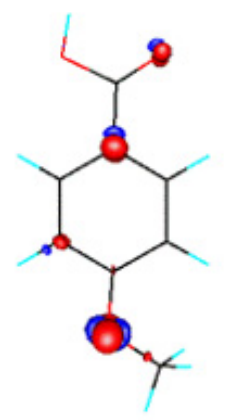

3b

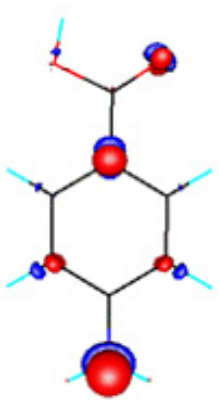

Figure 3. The surface plot of the electrophilic Fukui function $f^{-}(\mathbf{r})$ for the benzoic acids with electron-releasing substituent (1a-3c).

For the benzoic acid with the electron-withdrawing substituents (4a-6c) we examined the Fukui function for nucleophilic attack $f^{+}(\mathbf{r})$. Figure 4 shows that $f^{+}(\mathbf{r})$ is located in several atoms of the molecules $4 \mathbf{a}-\mathbf{6 c}$. As the substituent changes its position from ortho to para, the contribution of the $\mathrm{C}-2$ atom increases. The C-2 atom will increase its reactivity because in the electronic redistribution it is suitable to gain electron to a nucleophile and according with the local HSAB principle [23] it will interact with soft nucleophiles. The C-2 atom will be poor in electron density, and it will interact with the carboxyl group and allow the hydrogen atom to disassociate as a proton more easily. Therefore, the electron-releasing substituent $\left(\mathrm{CF}_{3}, \mathrm{NO}_{2}\right.$ and $\left.\mathrm{CF}_{3} \mathrm{SO}_{2}\right)$ will increase the acidity of the benzoic acid in the trend para- > meta- > ortho-position. 


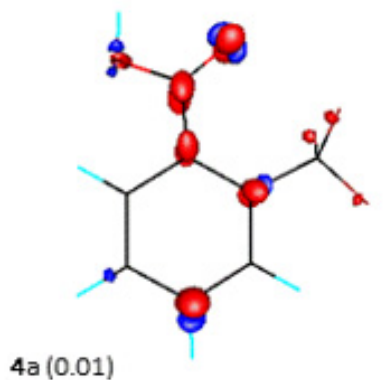

$4 \mathrm{a}(0.01)$

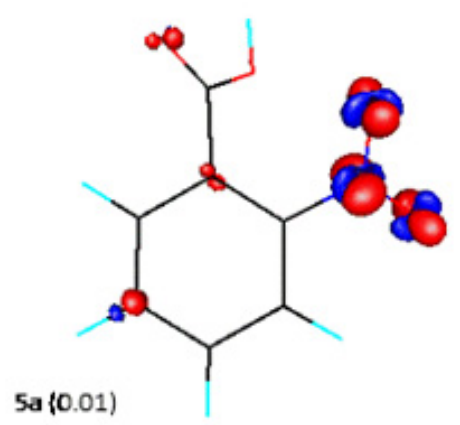

$5 a\{0.01)$

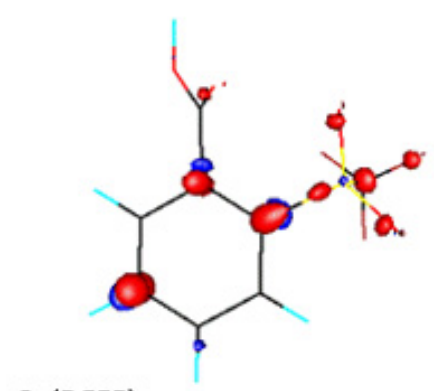

$5 b$

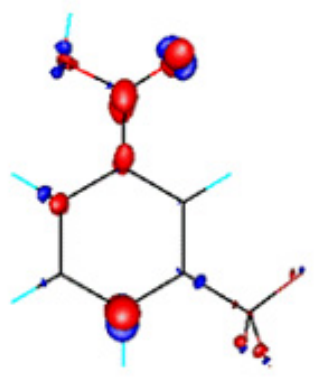

$4 b$

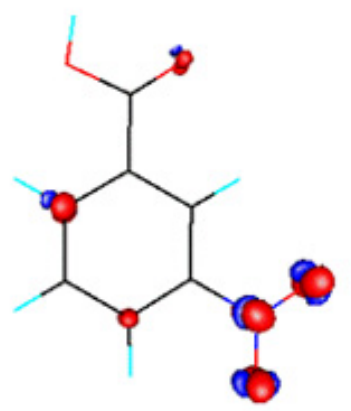

5

$4 c$

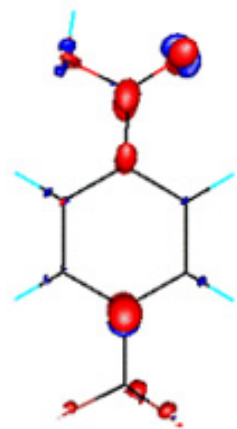<smiles>CCC(=O)C1=C(C)C(C)C(C(=O)O)C(C)C1C</smiles>

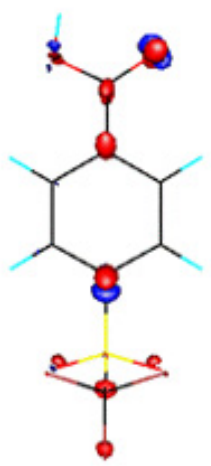

Figure 4. The surface plot of the nucleophilic Fukui function $f^{+}(\mathbf{r})$ for the benzoic acids with electron-withdrawing substituent $(\mathbf{4 a - 6 c )}$.

The previous results suggest that the inductive and resonance effects are more important than the polarizability effects in the acidity of substituted benzoic acids, and the inductive and resonance effects (IE and RE, respectively) of the substituent can be approximated as the difference of the gas phase acidity values between the two extremes: $\mathrm{IE}($ ortho $)=\Delta_{\text {acid }} G_{\text {ortho }}^{\circ}\left(-\mathrm{CH}_{3}\right)-\Delta_{\text {acid }} G_{\text {ortho }}^{\circ}\left(-\mathrm{SO}_{2} \mathrm{CF}_{3}\right)$, $\operatorname{IE}($ meta $)=\Delta_{\text {acid }} G_{\text {meta }}^{\circ}\left(-\mathrm{CH}_{3}\right)-\Delta_{\text {acid }} G_{\text {meta }}^{\circ}\left(-\mathrm{SO}_{2} \mathrm{CF}_{3}\right), \mathrm{IE}($ para $) \Delta_{\text {acid }} G_{\text {para }}^{\circ}\left(-\mathrm{CH}_{3}\right)-\Delta_{\text {acid }} G_{\text {para }}^{\circ}\left(-\mathrm{SO}_{2} \mathrm{CF}_{3}\right)$, $\operatorname{RE}\left(\mathrm{CH}_{3}\right)=\Delta_{\text {acid }} \mathrm{G}_{\text {para }}\left(-\mathrm{CH}_{3}\right)-\Delta_{\text {acid }} G^{\circ}$ ortho $\left(-\mathrm{CH}_{3}\right), \ldots, \operatorname{RE}\left(-\mathrm{SO}_{2} \mathrm{CF}_{3}\right)=\Delta_{\text {acid }} \mathrm{G}_{\text {ortho }}^{\circ}\left(-\mathrm{SO}_{2} \mathrm{CF}_{3}\right)-$ $\Delta_{\text {acid }} \mathrm{G}_{\text {para }}^{\circ}\left(-\mathrm{SO}_{2} \mathrm{CF}_{3}\right)$. With the calculated absolute gas phase acidity (Table 1$)$ we can obtain the contribution of the resonance and inductive effects for 1a-6c. Table 4 shows that in general the percentage contributions of the inductive effect is higher than the resonance effect. As we expected, the highest inductive and resonance effects are for the $-\mathrm{SO}_{2} \mathrm{CF}_{3}$ and $-\mathrm{NH}_{2}$ substituents in the para- and ortho-position, respectively. 
Table 4. Percentage contribution of resonance and inductive effects for the substituted benzoic acids. The percentage for the inductive effect is given in parentheses.

\begin{tabular}{ccccccc}
\hline & $\mathbf{1}$ & $\mathbf{2}$ & $\mathbf{3}$ & $\mathbf{4}$ & $\mathbf{5}$ & $\mathbf{6}$ \\
\hline \multirow{2}{*}{$\mathrm{a}$} & $18.79 \%$ & $31.26 \%$ & $43.31 \%$ & $19.78 \%$ & $22.69 \%$ & $18.20 \%$ \\
& $(81.21 \%)$ & $(68.74 \%)$ & $(56.69 \%)$ & $(80.22 \%)$ & $(77.31 \%)$ & $(81.80 \%)$ \\
$\mathrm{b}$ & $15.51 \%$ & $25.80 \%$ & $35.76 \%$ & $16.33 \%$ & $18.74 \%$ & $15.03 \%$ \\
& $(84.49 \%)$ & $(74.20 \%)$ & $(64.24 \%)$ & $(83.67 \%)$ & $(81.26 \%)$ & $(84.97 \%)$ \\
& $13.71 \%$ & $22.82 \%$ & $31.61 \%$ & $14.44 \%$ & $16.57 \%$ & $13.29 \%$ \\
$\mathrm{c}$ & $(86.29 \%)$ & $(77.18 \%)$ & $(68.39 \%)$ & $(85.56 \%)$ & $(83.43 \%)$ & $(86.71 \%)$ \\
\hline
\end{tabular}

\section{Methodology and Computational Details}

The ground state structures, energies and gas phase acidities of the ortho-, meta- and para-substituted benzoic acids $1 a-6 c$ were calculated at the B3LYP/6-311++G(2d,2p) level of theory using GAUSSIAN09 [30]. Please find the information of Computed Cartesian Coordinates and Energies of Substituted Benzoic Acids in the Supplementary Materials. The default SCF = TIGHT convergence was used: convergence on RMS density matrix $=1.00 \mathrm{D}-08$ within 64 cycles, convergence on MAX density matrix $=1.00 \mathrm{D}-06$, and convergence on energy $=1.00 \mathrm{D}-06$. The absolute gas-phase acidity $\Delta_{\text {acid }} G^{\circ}$ was obtained using $\Delta_{\text {acid }} G^{\circ}=G^{\circ}$ (anion) $+G^{\circ}\left(\mathrm{H}^{+}\right)-G^{\circ}$ (acid). The Gibbs free energy of the proton in the gas phase $G^{\circ}\left(\mathrm{H}^{+}\right)=-6.26 \mathrm{kcal} / \mathrm{mol}$ was obtained by means of partition functions using statistical thermodynamic relationships [35]. All of thermodynamics parameters were obtained at $\mathrm{T}=298.15 \mathrm{~K}$ and $\mathrm{P}=1 \mathrm{~atm}$. The Fukui functions for electrophilic and nucleophilic attacks of $\mathbf{1 a}-\mathbf{6 c}$ were visualized by the gOpenmol software [36]. Frequency calculations were carried out without any symmetry constraints to confirm that the structures obtained correspond to energy minima. In order to corroborate the quality of the B3LYP functional we made calculations of the gas phase acidity using $\mathrm{MP} / 6-311++\mathrm{G}(2 \mathrm{~d}, 2 \mathrm{p})$ and the M062X/6-311++G(2d,2p) levels of theory. The agreement between the calculated and experimental gas phase acidity values of benzoic acids was -3.14 to $+6.97 \mathrm{kcal} / \mathrm{mol}$ for M062X, -2.70 to 0.04 for MP2 and -2.60 to $1.99 \mathrm{kcal} / \mathrm{mol}$ for B3LYP, the experimental uncertainty was -2.01 to $2.01 \mathrm{kcal} / \mathrm{mol}$, therefore B3LYP was very good within the expected experimental uncertainty. We characterized the conformational space of the species and found that conformers with the $\mathrm{O}=\mathrm{C}-\mathrm{O}-\mathrm{H}$ dihedral close to zero give better gas phase acidity values than the $\mathrm{O}=\mathrm{C}-\mathrm{O}-\mathrm{H}$ dihedral close to $180^{\circ}$. For example the gas phase acidity for ortho-amino substituent with the $\mathrm{O}=\mathrm{C}-\mathrm{O}-\mathrm{H}$ dihedral near to $180^{\circ}$ was $322.51 \mathrm{kcal} / \mathrm{mol}$ and for $0^{\circ}$ was $331.04 \mathrm{kcal} / \mathrm{mol}$, respectively; the experimental value is $330.31 \pm 2.01 \mathrm{kcal} / \mathrm{mol}$. The conformational analysis showed no disagreement in the DFT descriptors due to the change of the dihedral angle $\mathrm{O}=\mathrm{C}-\mathrm{O}-\mathrm{H}$ from 0 to 180 degrees; we observed that the linear relations of free energy between acidity and the DFT descriptors do not depend on the conformational peculiarities of this molecule. We compared the electrophilic and nucleophilic Parr function [37] for the ortho-, meta- and para-substituted benzoic acids 1a-6c and we obtained not difference with the Yang and Mortier Fukui functions.

\section{Conclusions}

The electronegativity and the Fukui function are good descriptors to account for substituent effects in the gas phase acidity of a set of ortho-, meta and para-substituted benzoic acids. The analysis of inductive and resonance effects of the substituent in the acidity of substituted benzoic acids shows that they contribute in the opposite way, for electron-withdrawing substituent the acidity increases from ortho- to para-isomers when the inductive and resonance effects increases and decreases, respectively, while for electron-releasing substituent the acidity increases from para- to ortho-isomers when the inductive and resonance effects decreases and increases, respectively. The highest inductive and resonance effects are for the $-\mathrm{SO}_{2} \mathrm{CF}_{3}$ (electron-withdrawing) and $-\mathrm{NH}_{2}$ (electron-releasing) substituents in the para- and ortho-position, respectively. The acidity difference between the para- $\mathrm{SO}_{2} \mathrm{CF}_{3}$ and ortho- $\mathrm{NH}_{2}$ benzoic acids is $14.16 \mathrm{kcal} / \mathrm{mol}$. Recently, Georgousaki et al. [38] have pointed out the great 
importance of substituted benzoic acids in biology. They suggested that the $p$-hydroxybenzoic acid can be considered as a promising candidate for the development of novel modulators of the proteostasis network, and likely of anti-aging agents. They showed that benzoic acid derivatives substituted with $\mathrm{OH}, \mathrm{CH}_{3}$ and $\mathrm{Cl}$ enhance the activity of the two main cell protein degradation systems (the ubiquitin-proteasome and the autophagy-lysosome pathway) and especially the activity of cathepsins $B$ and L. We hope that our results will open up the possibility of analyzing the chemical-biological interactions of substituted benzoic acids in terms of DFT reactivity descriptors.

Supplementary Materials: Supplementary materials can be accessed at, Computed Cartesian Coordinates and Energies of Substituted Benzoic Acids (Page 2S), Computed Hirshfeld Atomic Charges (Page 18S), Electronegativity and Global Softness (Page 24S), Condensed Fukui Function Calculated Using Hirshfeld Atomic Charges (Page 25S), Absolute gas phase acidities for 1a-6c calculated at the M062X/6-311++G(2d,2p) and MP2/6-311++G(2d,2p) levels of theory (Page 29S).

Author Contributions: Conceptualization, R.E.R. and F.M.; Data curation, J.A.A.-B. and M.-A.M.-S.; Formal analysis, F.M.; Funding acquisition, R.E.R.; Investigation, J.A.A.-B., R.E.R. and F.M.; Methodology, F.M.; Project administration, R.E.R. and F.M.; Software, J.A.A.-B., M.-A.M.-S. and F.J.M.; Supervision, R.E.R.; Writing original draft, R.E.R. and F.M.; Writing-review \& editing, F.M. All authors have read and agreed to the published version of the manuscript.

Funding: This work was partially supported by a) "PROGRAMA DE ESTÍMULOS A LA INVESTIGACIÓN PARA DOCTORAS Y DOCTORES 2018" en el área de BIOLOGÍA Y QUÍMICA, Cuerpo Académico BUAP-CA-263 "Investigación experimental-computacional de nuevos materiales y sistemas biomoleculares". Laboratorio Nacional de Supercómputo del Sureste de México (LNS), and b) Programa Especial de Apoyo a la Investigación Básica UAM-2019.

Acknowledgments: The authors wish to thank the Laboratorio Nacional de Supercómputo del Sureste de México (LNS).

Conflicts of Interest: The authors declare no conflict of interest.

\section{References}

1. Hammett, L.P. Physical Organic Chemistry, 2nd ed.; McGraw-Hill: New York, NY, USA, 1970; pp. $146-177$. ISBN 978-0070259058.

2. Exner, O.; Böhm, S. Background of the Hammett Equation As Observed for Isolated Molecules: Meta- and Para-Substituted Benzoic Acids. J. Org. Chem. 2002, 67, 6320-6327. [CrossRef]

3. Böhm, S.; Fiedller, P.; Exner, O. Analysis of the ortho effect: Acidity of 2-substituted benzoic acids. New J. Chem. 2004, 28, 67-74. [CrossRef]

4. Verevkin, S.P.; Zaitsau, D.H.; Emel'yanenko, V.N.; Stepurko, E.N.; Zherikova, K.V. Benzoic acid derivatives: Evaluation of thermochemical properties with complementary experimental and computational method. Thermochim. Acta 2015, 622, 18-30. [CrossRef]

5. Taft, R.W.; Topsom, R.D. The Nature and Analysis of substitutent electronic effects Prog. Phys. Org. Chem. 1987, 16, 1-83. [CrossRef]

6. Taft, R.W.; Koppel, I.A.; Topsom, R.D.; Anvia, F. Acidities of OH compounds, including alcohols, phenol, carboxylic acids, and mineral acids. J. Am. Chem. Soc. 1990, 112, 2047-2052. [CrossRef]

7. Abboud, J.-L.M.; Catalán, J.; Elguero, J.; Taft, W. Polarizability effects on the aqueous solution basicity of substituted pyridines. J. Org. Chem. 1987, 53, 1137-1140. [CrossRef]

8. Roithova, J.; Exner, O. Protonation of alkylpyridines: Polarizability and steric effects in the base and in the cation. J. Phys. Org. Chem. 2001, 14, 752-758. [CrossRef]

9. Kulhánek, J.; Decouzon, M.; Gal, J.-F.; Maria, P.-C.; Fiedler, P.; Jiménez, P.; Roux, M.-V.; Exner, O. Steric effect and steric hindrance to resonance in tert-butylbenzoic acids in the gas phase and the solution. Eur. J. Org. Chem. 1999, 1999, 1589-1594. [CrossRef]

10. De Proft, F.; Langenaeker, W.; Geerlings, P. Ab initio determination of substituent constants in a Density Functional Theory formalism: Calculation of intrinsic group electronegativity, hardness and softness. J. Phys. Chem. 1993, 97, 1826-1831. [CrossRef]

11. De Proft, F.; Amira, S.; Choho, K.; Geerlings, P. Quantum Chemical Study of the acidity of substituted acetic acids with density functional theory based descriptors. J. Phys. Chem. 1994, 98, 5227-5233. [CrossRef] 
12. Gupta, K.; Giria, S.; Chattaraj, P.K. Acidity of meta- and para-substituted aromatic acids: A conceptual DFT study. New, J. Chem. 2008, 32, 1945-1952. [CrossRef]

13. Huang, Y.; Liu, L.; Liu, W.; Liu, S.; Liu, S. Modeling Molecular Acidity with Electronic Properties and Hammett Constants for Substituted Benzoic Acids. J. Phys. Chem. A 2011, 115, 14697-14707. [CrossRef] [PubMed]

14. Vianello, R.; Maksic, Z.B. Gas-phase acidity of para-substituted benzoic acids-A triadic analysis of substituent effects. J. Phys. Org. Chem. 2005, 18, 699-705. [CrossRef]

15. Hollingsworth, C.A.; Seybold, P.G.; Hadad, C.M. Substituent Effects on the Electronic Structure and pKa of Benzoic Acid. Int. J. Quantum Chem. 2002, 90, 1396-1403. [CrossRef]

16. Romero María de, L.; Méndez, F. Is the Hydrogen Atomic Charge Representative of the Acidity of Parasubstituted Phenols? J. Phys. Chem. A 2003, 107, 4526-4530. [CrossRef]

17. Méndez, F.; Romero, M.L.; De Proft, F.; Geerlings, P. The basicity of $p$-substituted phenolates and the elimination-substitution ratio in $p$-nitrophenethyl bromide: A HSAB theoretical study. J. Org. Chem. 1998, 63, 5774-5778. [CrossRef]

18. Romero, M.L.; Méndez, F. The local HSAB principle and the bond dissociation energy of $p$-substituted phenols. J. Phys. Chem. A 2003, 107, 5874-5875. [CrossRef]

19. Ramírez, E.R.; García-Martínez, C.; Méndez, F. Influence of fluorine atoms and aromatic rings on the acidity of ethanol. J. Phys. Chem. A 2009, 113, 10753-10758. [CrossRef]

20. Ramírez, E.R.; García-Martínez, C.; Méndez, F. Understanding the Nucleophilic Character and Stability of the Carbanions and Alkoxides of 1-(9-Anthryl)ethanol and Derivatives. Molecules 2013, 18, 10254-10265. [CrossRef]

21. Parr, R.G.; Yang, W. Density Functional Theory of Atoms and Molecules; Oxford University Press: New York, NY, USA, 1989; pp. 47-67, 978-0195092769.

22. Pearson, R.G. Hard and soft acids and bases. J. Am. Chem. Soc. 1963, 85, 3533-3539. [CrossRef]

23. Méndez, F.; Gázquez, J.L. Chemical reactivity of enolate ions: The local hard and soft acids and bases principle viewpoint. J. Am. Chem. Soc. 1994, 116, 9298-9301. [CrossRef]

24. Vela, A.; Gázquez, J.L. A relationship between the static dipole polarizability, the global softness, and the fukui function. J. Am. Chem. Soc. 1990, 12, 1490-1492. [CrossRef]

25. Roy, R.; Chandra, A.K.; Pal, S. Correlation of Polarizability, Hardness, and Electronegativity: Polyatomic Molecules. J. Phys. Chem. 1994, 98, 10447-10450. [CrossRef]

26. Boisdenghien, Z.; Fias, S.; Da Pieve, F.; De Proft, F.; Geerlings, P. The polarizability of atoms and molecules: A comparison between a conceptual density functional theory approach and time-dependent density functional theory. Mol. Phys. 2015, 113, 1890-1898. [CrossRef]

27. Komorowski, L.; Lipinski, J.; Szarek, P.; Ordon, P. Polarization justified Fukui functions: The theory and applications for molecules. J. Chem. Phys. 2011, 135, 014109. [CrossRef]

28. Krishtal, A.; Senet, P.; Van Alsenoy, C. Local softness, softness dipole and polarizabilities of functional groups: Application to the side chains of the twenty amino acids. J. Chem. Phys. 2009, 131, 044312. [CrossRef]

29. López, P.; Méndez, F. Fukui function as a descriptor of the imidazolium protonated cation resonance hybrid structure. Org. Lett. 2004, 6, 1781-1783. [CrossRef]

30. Frisch, M.J.; Trucks, G.W.; Schlegel, H.B.; Scuseria, G.E.; Robb, M.A.; Cheeseman, J.R.; Scalmani, G.; Barone, V.; Mennucci, B.; Petersson, G.A.; et al. Gaussian 09; Gaussian, Inc.: Wallingford, CT, USA, 2009.

31. NIST Chemistry Web Book. Available online: http://webbook.nist.gov/chemistry/(accessed on 12 May 2019).

32. Yang, W.; Mortier, W.J. The use of global and local molecular parameters for the analysis of the gas phase basicity of amines. J. Am. Chem. Soc. 1986, 108, 5708-5711. [CrossRef]

33. Hirshfeld, F.L. Bonded-atom fragments for describing molecular charge densities. Theoret. Chim. Acta (Berl.) 1977, 44, 129-138. [CrossRef]

34. Parr, R.G.; Yang, W. Density functional approach to the frontier-electron theory of chemical reactivity. J. Am. Chem. Soc. 1984, 106, 4049-4050. [CrossRef]

35. Levine, I. Quantum Chemistry, 5th ed.; Prentice Hall: Upper Saddle River, NJ, USA, 2001; pp. 154-196, 414-415, 0136855121.

36. Laaksonen, L. gOpenMol, Center for Scientific Computing: Espoo, Finland. 
37. Domingo, L.R.; Pérez, P.; Sáezc, J.A. Understanding the local reactivity in polar organic reactions through electrophilic and nucleophilic Parr function. RSC Adv. 2013, 3, 1486-1494. [CrossRef]

38. Georgousaki, K.; Tsafantakis, N.; Gumeni, S.; Lambrinidis, G.; González-Menéndez, V.; Tormo, J.R.; Genilloud, O.; Trougakos, I.P.; Fokialakis, N. Biological Evaluation and In Silico Study of Benzoic Acid Derivatives from Bjerkandera adusta Targeting Proteostasis Network Modules. Molecules 2020, 25, 666. [CrossRef] [PubMed]

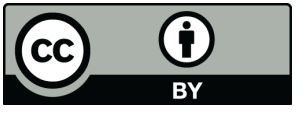

(C) 2020 by the authors. Licensee MDPI, Basel, Switzerland. This article is an open access article distributed under the terms and conditions of the Creative Commons Attribution (CC BY) license (http://creativecommons.org/licenses/by/4.0/). 